\title{
Controls on Chemical Weathering and Physical Erosion in a Mixed Carbonate-Siliciclastic Orogen
}

\author{
ERICA ERLANGER ${ }^{1}$, JEREMY CAVES RUGENSTEIN ${ }^{2}$, \\ AARON BUFE ${ }^{1}$, VINCENZO PICOTTI ${ }^{3}$ AND SEAN \\ WILLET $^{3}$ \\ ${ }^{1}$ GFZ Potsdam \\ ${ }^{2}$ Colorado State University \\ ${ }^{3}$ ETH Zurich \\ Presenting Author: ederlanger@gmail.com
}

Mixed siliciclastic and carbonate orogens are common on Earth's surface, yet the processes that control erosion and weathering in such landscapes are poorly understood, because existing studies have focused on erosion and weathering in silicate-rich landscapes. Silicate weathering sequesters atmospheric $\mathrm{CO}_{2}$, and late Cenozoic erosion of mountain belts has been hypothesized to have increased silicate weathering efficiency, cooling the planet. However, most active mountain belts are comprised of mixed carbonate and silicate lithologies, and the response of erosion and weathering to uplift in these mixed-lithology ranges may differ from purely siliciclastic landscapes. A lack of studies on the physical and chemical erosion of mixed carbonate-silicate lithologies thus limits our knowledge on the mechanistic coupling between uplift, chemical weathering, and the carbon cycle. Here, we partition denudation fluxes into physical erosion and chemical weathering of carbonates and silicates in the Northern Apennine Mountains of Italy - a mixed carbonate-siliciclastic active orogen-using dissolved solutes, the fraction of carbonate sand in sediments, and existing ${ }^{10} \mathrm{Be}$ denudation rates. We find that physical erosion fluxes are generally an order of magnitude higher than chemical weathering fluxes and dominate total denudation. Across the study area, the contribution of carbonate and silicate minerals to the physical erosion flux varies between lithologic units, but weathering fluxes are systematically dominated by carbonates. Whereas silicate weathering may be limited by reaction rates, carbonate weathering may be limited by acidity of the rivers that drain the orogen. Precipitation of secondary calcite from supersaturated streams leads to the loss of up to $90 \%$ of dissolved $\mathrm{Ca}^{2+}$ from carbonate-rich catchments. Thus, in the weathering zone, $\left[\mathrm{Ca}^{2+}\right]$ is exceptionally high, likely driven by high soil $p \mathrm{CO}_{2}$; however, re-equilibration with atmospheric $p \mathrm{CO}_{2}$ in rivers converts solutes back into solid grains that become part of the physical denudation flux. Limits on weathering in this landscape therefore differ between the subsurface weathering zone and what is exported by rivers. 